\title{
Unidirectionality in Grammaticalization and Lexical Shift: The Case of English Rather
}

\author{
MATTHEW L. JUGE \\ Southwest Texas State University
}

\section{Traditional models of grammaticalization}

Traditional models of grammaticalization posit a process (or a set of processes) whereby words belonging to one lexical class shift to another lexical class considered to be more grammatical, as illustrated schematically in Figure 1, adapted from Hopper \& Traugott 1993:108).

Figure 1-Typical one-dimensional model of verb grammaticalization full verb $>$ auxiliary $>$ clitic $>$ affix

In this paper I argue that the seemingly unrelated shift of English rather from comparative adverb to verb shows that such a model for grammaticalization is untenable.

\section{Subprocesses of grammaticalization}

Newmeyer argues (1998:252-259) that many of the processes that comprise grammaticalization are not unique to grammaticalization. In addition to the examples he provides, consider the following examples:

- phonological reduction

- inferential change

- metaphor

- harmony

\begin{abstract}
English says [sєz] (cf. pays [pejz])
English want 'lack' > 'desire'

Gothic wait 'I have seen/I saw' > 'I know'

English picker-upper, rathering interesting
\end{abstract}

With the integrity of grammaticalization as a coherent process in jeopardy, it now becomes even more important than ever to clearly identify what the components of grammaticalization are and how they relate to other kinds of linguistic changes. First, I will explore some earlier treatments of unidirectionality. 


\section{Previous arguments against unidirectionality}

Other authors have argued that grammaticalization is not a unidirectional process, among them Newmeyer (1998), Beths (1999), and Janda (2001), while Ramat (1992) provides a number of counterexamples to the unidirectionality hypothesis.

Newmeyer argues quite strongly against the unidirectionality hypothesis. Part of his claim depends on the assertion-supported with extensive argumentation and examples (1998:232-59) - that grammaticalization is not a distinct process of its own. He further argues that, if it were a process in any meaningful sense of the term, it would, like aging, erosion, or evolution be uninterestingly unidirectional.

A key consideration that Newmeyer raises concerns the distinction between those grammaticalization researchers who treat unidirectionality essentially as part of the definition of grammaticalization and those who treat it as an empirical hypothesis or claim, in which case, he writes, '[T]he claim is false' (1998:261). Newmeyer suggests that for those who treat unidirectionality as a part of the definition of grammaticalization, there is no arguing, since definitions cannot be right or wrong.

Beths (1999) develops an argument against unidirectionality in the context of an in-depth analysis of a specific verb, claiming,

\footnotetext{
The historical development of dare, from a semilexical verb in $\mathrm{O}[\mathrm{ld}] \mathrm{E}$ [nglish], to a modal auxiliary, a lexical verb, and a semimodal verb in Mod[ern ]E[nglish] shows that grammaticalization can no longer be considered to be a unidirectional diachronic process of language change. (1999:1105)
}

Finally, Janda focuses on the discontinuous nature of language transmission and the fact that scholars have generally ignored this fact, paying attention instead to linguistic forms themselves.

In short, it now seems clear that, if there is not yet consensus, there is certainly a growing body of literature expressing the idea that the claim of unidirectionality is simply false.

But I wish to argue that all these researchers are missing an important point. In discussing unidirectionality and reversability, these scholars reveal that they are working with a one-dimensional model of lexical categories. The evidence shows that a multi-dimensional model is required to accommodate the various types of changes we see in the data, some of which are illustrated by the history of English rather, to which I now turn.

\section{Lexical shift}

In this section I would like to put aside questions of unidirectionality momentarily and address one of the similarities between grammaticalization and another kind of language change, namely lexical shift, called transcategorization by Ramat (2001). This is the shift of a linguistic unit, usually a word, from one lexical class to another. For example, in English, the participle during has shifted to the class of prepositions. 
I want to explore these two (putative) phenomena together because grammaticalization frequently involves lexical shift. Thus, if we are to understand grammaticalization-and any unidirectionality it may show-then we must first understand lexical shift. In order to do this, I will perform a case study of the English word rather.

\section{Rather}

In modern English, the word rather has as one of its uses a verbal usage whereby it marks preference, as in (1).

(1) She hates listening about castles,/She rathers the battles. (http://homepage.tinet.ie/ portlawns/Pages/poems.htm)

This non-standard usage is further exemplified in the Appendix.

\subsection{English}

Historically rather is a comparative adverb meaning 'sooner, more quickly', as shown in the following example from around 1475 (Simpson \& Weiner 1989):

(2) This worle..goth vnto decline, Rather or later to an endly fine.

Such a meaning is suitable in the right circumstances for expressing preference, as we see in (3):

(3) I would sooner cut off my right arm than be converted to right-handedness.... (from http://www.emf.net/ estephen/facts/lefthand.html)

In this situation, the expression of preference depends on two main components: (a) the real-world knowledge that cutting off one's right arm is a dispreferred action (even for a southpaw!) and (b) the tendency to, when possible, do what we like doing before doing things we do not like doing. We have here a case of pragmatic implicature (sometimes called inferential change in the grammaticalization literature) that allows the addressee to realize that the writer is so fond of left-handedness that, given the choice of losing it or their right arm, they would give up their right arm.

With rather the common pragmatic implicature of preference ultimately came to outshine the temporal meaning. This process was aided by the loss of the positive and superlative forms rathe and rathest, respectively, around the sixteenth century (contrast sooner, which the speaker can easily relate to the positive and superlative soon and soonest).

It is important at this point to note that because English lexical classes do not have characteristic morphological structures, rather does not advertise its status as an adverb, having essentially the same structure as the noun lather and the verb gather. This morphological ambiguity makes rather well-suited for 
reinterpretation as a word of virtually any lexical class, but I will focus exclusively on the verbal use and ignore other uses, including the adverbial degree usage (It's rather cold in here) and the compound prepositional usage ( $I$ had a salad rather than a burger).

Let us now consider the placement of rather relative to the verbal elements with which it frequently appears, namely would and have. Examples (4-10) show that English is flexible not just with rather but with the placement of adverbials in general.

(4) I gladly would've paid the extra $\$ 20 \ldots$.

(http://www.mexconnect.com/mex_/jrrimmig.html)

(5) I would gladly have paid twice the amount....

(http://www.pcesoft.com/)

(6) I would have gladly ransomed him....

(http://www.audiencemag.com/archives.html)

(7) We would have rather had a trial by ourselves.

(http://www.cnn.com/2001/LAW/01/29/combs.trial.02/index.html)

(8) ...I would have rathered a contractor do this.

(http://www.easton.ma.us/Directory/selectmen/minutes/min9-5-00.htm)

(9) I would rather a person (including entered contenstants) didn't win mr.net.art (http://bak.spc.org/iod/MisterNet.Art.html)

(10) I would rather a year of suffering than a week of living the mundane (http://www.pagans.org/ fyrecat/fyrecat/lyght.html)

This flexibility is not without pattern, however. Table 1, the results of a search of three patterns on the World Wide Web, shows that in cases in which rather appears with would and have, there is an overwhelming tendency for it to come between them.

Table 1-Frequency of patterns of rather and the verbal complex

\begin{tabular}{|l|r|}
\hline I rather would have & 80 \\
\hline I would rather have & 19097 \\
\hline I would have rather & 2990 \\
\hline
\end{tabular}

This positioning of rather gives it the appearance of a second auxiliary marking preference. 
The next piece of the conspiracy to make rather look like a verb concerns the behavior of would. Historically it is the past tense of will, which as a main verb used to mean 'to want'. It also was the past subjunctive of will, with the meaning 'would like', but this usage has faded into disuse:

(11) *I would one of those chocolate chip cookies.

The loss of this main verb use of would leaves the phrase would rather (11) looking like a phrase consisting of an auxiliary (would) and a main verb (rather).

$$
\text { “...or would you rather coffee?" }
$$

(http://www.lisacerasoli.com/fanfic/authors/rebecca/memories/memories8.html)

Once rather was (re)interpreted as a verb, the door was opened to the analogical formation of additional verb forms, including past tense rathered, participial rathered, and third singular non-past rathers.

The exact chronology of some of these changes is difficult if not impossible to ascertain since some of the uses are non-standard and thus unlikely to be recorded, except on the internet (see $\S 7$ for further discussion of this point).

So, difficulties in dating certain changes notwithstanding, we may summarize the development of rather from adverb to main verb as follows:

\section{chronology of rather}

1. positive rathe and superlative rathest lost in modern English

2. loss of earlier temporal meaning of rather

3. un(der)specified morphological structure: cf. noun lather, verb gather

4. rather between would and a main verb - appearance of a second auxiliary

5. loss of would as subjunctive equivalent to would like

6. reinterpretation of rather as a verb

7. analogical past tense, past participle rathered, third singular nonpast rathers

\subsection{Brief comparison with Italian piuttosto}

It may be useful at this point to explore why cases of the kind of shift shown by rather are not more common. To do this, I examine the potentially equivalent term in Italian, piuttosto, exemplified in (13).

(13) piuttosto andrei a chiedere l'elemosina '...I would rather go ask for alms.' (http://www.theo.it/R\&L/inmorte.html)

Like rather, piuttosto has the appearance of a comparative form (>più 'more' + tosto 'soon'), although since tosto is now literary, there is a certain opacity to 
the form. Again like rather, there is a separate root that now means 'soon', presto. Quite unlike rather, however, piuttosto does not resemble a verb (except that it ends in -o like first person singular indicative forms).

In Italian, the chance that an adverb will essentially accidentally resemble a verb, inflected or otherwise, is slim because verbs have a characteristic set of shapes, while in English this is not the case. In the end, a number of factors have to come together for the kind of shift shown by rather to take place. Thus we do not see such changes often. Since this type of change is one of the major kinds that contradict the appearance of unidirectionality and it is relatively infrequent, researchers have been led to believe that (apparent) unidirectionality is a significant phenomenon.

\section{A unified model of lexical category change}

The case of rather, then, suggests a model of language change that does not rely on a simple, one-dimensional view of language, but rather a conceptualization of lexical space with at least two dimensions, if not more (see Figure 2).

Figure 2-A two-dimensional model for category changes

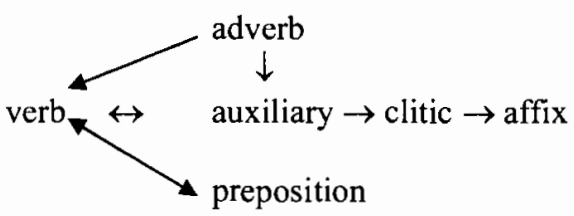

On such a view of the relationships among lexical categories, the debate over unidirectionality takes on a less compelling character. At the same time, we are more likely to recognize patterns previously overlooked because researchers were only looking in a restricted set of places for their data.

\section{Coda: Lowered standards and improved research}

In the course of conducting the research for this paper, I was reminded of certain difficulties associated with researching non-standard language forms. Beyond the well-known obersver's paradox is the fact that in certain kinds of contexts, the very fact that these forms are non-standard excludes them from appearing. In this section I argue that the relatively untamed nature of the World Wide Web is a boon to the linguistic researcher working on some kinds of non-standard patterns.

While some might think of the internet as a place where important standards are being violated daily, in my research I found that not only is there a great degree of systematicity and order-how could it be otherwise if the medium is to be used for communication? - but that there is also the added benefit of increased likelihood of appearance of certain linguistic forms. The case of rather shows this well, for when we compare a corpus of materials that adhere fairly well to these standards, namely the SARA corpus (http://sara.natcorp.ox.ac.uk/lookup.html), 
we find no examples of verbal rather, while on the Internet, we find many examples.

\subsection{Complications associated with 'lowered' standards}

Along with the increased research possibilities of the unregulated nature of the internet come certain complications. Foremost among these is that when using the internet as a corpus, one must keep in mind that some tasks will require extra effort. One example is performing word frequency counts or distribution analyses; a search for receive, for instance, would be more successful if one also searched for recieve (and possibly other variants). Of course there is a good chance that additional variants may occur that the researcher will not be able to anticipate, but the same is true of research with an unfamiliar spoken language.

\subsection{Directions for future research on the Internet}

My experience in researching the distribution of verbal rather strongly suggests that use of the internet as a new kind of corpus holds a great deal of promise so long as researchers keep in mind, as they should in all research situations, the importance of context to data they obtain.

\section{Appendix: Examples of verbal rather}

Zionism was born in the late $1800 \mathrm{~s}$, the Jews did not want to leave their countires, no need to mention on how the Zionists were fought \& attack, both politically \& physically, by the Jewish peoples across europe, but thanks to the Holocaust that left the Jews to no choice but to immigrate to Russia, US, and England, you know like every one esle know that the bulk of the Jews rathered to go to russia than going to the "Promised land".

LBJ much rathered to fight a war against poverty and make his vision of a Great Society a reality, but performing in the shadow of an assassinated president did not afford him that luxury.

Webster noted for $2.2 \mathrm{~m}$ I would have rathered a contractor do this.

But I would have rathered a slightly better pc for slightly more...

"I think the players would have rathered to play on when the break came, but we have the chance when we go back to show what we can do again."

Erris themselves would have rathered to take the full Complement of points on offer but at least a point keeps them within touching distance of the leaders. www.salam-shalom.net/ salam-shalom/arcjan $27 . \mathrm{htm}$

www.coe.uh.edu/ hypergroups/courses/ hist3322/0043.html

www.easton.ma.us/Directory/ selectmen/minutes/min 9-5-00.h www.linuxsa.org.au/mailing-lis 2001-01/429.html www.celticfc.co.uk/newsdesk/ latest_news/0101/am_21_2009.htm www.mayo-ireland.ie/WPeople WP9809/WP980909/Sport.htm 


\section{References}

Aaron, Jane. 2001. The Little, Brown Compact Handbook. New York: Longman. Beths, Frank. The history of dare and the status of unidirectionality. Linguistics 37-6: $1069-1110$.

Hopper, Paul, and Elizabeth Traugott. 1993. Grammaticalization. Cambridge: Cambridge Univerisity Press.

Janda, Richard D. 2001. Beyond "pathways" and "unidirectionality": On the discontinuity of language transmission and the counterability of grammaticalization. Language Sciences 23: 265-340.

Ramat, Paolo. 1992. Thoughts on degrammaticalization. Linguistics 30: 549-60. 2001. Degrammaticalization or transcategorization? In Schaner-Wolles, Torino, Rosenberg, \& Sellier (eds.) Naturally! Linguistic studies in honour of W.U. Dressler presented on the occasion of his 60th birthday, 393-401.

Newmeyer, Frederick J. 1998. Lanuage Form and Language Function. Cambridge: Massachusetts Institute of Technology.

Simpson, J. A. \& E. S. C. Weiner, (eds.). 1989. The Oxford English Dictionary. Oxford: Oxford University Press.

Department of Modern Languages

214 Centennial Hall

601 University Dr.

Southwest Texas State University

San Marcos, TX 78666-4616

juge@modlang.swt.edu 